\title{
Retinopathy of Prematurity Is Associated with Increased Systolic Blood Pressure in Adults Who Were Born Preterm
}

\author{
Anna Kistner ${ }^{a, b}$ Lena Jacobson ${ }^{c}$ Jan Östergren ${ }^{d}$ Ann Hellström ${ }^{a}$

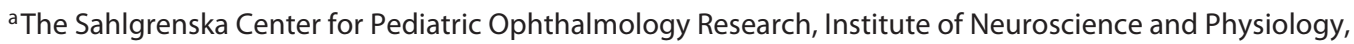 \\ Sahlgrenska Academy at University of Gothenburg, Gothenburg, and Departments of bolecular Medicine and \\ Surgery and ${ }^{\mathrm{C} C l i n i c a l}$ Neuroscience, Karolinska Institutet, and ${ }^{\mathrm{d} D e p a r t m e n t}$ of Medicine, Solna, Stockholm, Sweden
}

\section{Keywords}

Preterm · Retinopathy of prematurity · Blood pressure · Salivary cortisol

\begin{abstract}
Background: Adults born preterm are at risk of developing cardiovascular morbidities. Objective: The aim of this study was to evaluate the relationship between retinopathy of prematurity (ROP) and blood pressure (BP) and salivary cortisol levels during adulthood. Methods: Sixty-nine subjects (mean age 22.6 years) were included. Subjects were adults who were: (a) ex-preterm infants with severe ROP $(n=22)$, born at gestational age (GA) <30 weeks with a birth weight (BW) $<1,000 \mathrm{~g}$, (b) ex-preterm infants with no/mild ROP $(n=21)$, born at $\mathrm{GA}<28$ weeks with a $\mathrm{BW}<1,000 \mathrm{~g}$, or (c) full-term controls $(n=26)$. Anthropometric data, office BP, ambulatory $B P$, and morning and evening salivary cortisol were analyzed. Results: As adults, ex-preterm infants with severe ROP had on average $7.4 \mathrm{~mm} \mathrm{Hg}$ higher systolic office BP than those with no/mild ROP $(p=0.019)$ and controls $(p=0.007)$. A high cortisol level, tall height, and severe ROP were independent predictors of higher ambulatory systolic BP during adulthood in forward stepwise regression analysis, independent of GA.
\end{abstract}

\section{KARGER}

E-Mail karger@karger.com www.karger.com/neo
(C) 2017 The Author(s)

Published by S. Karger AG, Basel

Karger

Open access

This article is licensed under the Creative Commons AttributionNonCommercial-NoDerivatives 4.0 International License (CC BYNC-ND) (http://www.karger.com/Services/OpenAccessLicense). Usage and distribution for commercial purposes as well as any distribution of modified material requires written permission.
Conclusion: Our results indicate that preterm infants with severe abnormal retinal vascular development during the neonatal period may be at an increased risk for increased BP during adulthood. We found no differences between those with no/mild ROP as infants and controls with regard to BP data.

\footnotetext{
(C) 2017 The Author(s)

Published by S. Karger AG, Basel
}

\section{Introduction}

Preterm birth is associated with an increased risk of high blood pressure (BP) in young adulthood [1]. Immaturity and being born small for gestational age (GA) [1] are proposed to explain this association. Neonatal complications such as retinopathy of prematurity (ROP) [2] have also been associated with hypertension in children who were born preterm.

The present study evaluated the relationship between severe ROP during infancy and adult BP, physical activity, and salivary cortisol levels. Results were compared with individuals born very preterm without severe ROP and full-term controls. All study participants were part of a cohort born between 1988 and 1993 in Stockholm, Sweden. 
Table 1. Peri- and neonatal characteristics and current characteristics in adults born preterm with different grades of ROP during their early neonatal weeks (preterms), or born at full term with a normal BW (controls)

\begin{tabular}{|c|c|c|c|c|c|c|c|}
\hline & $\begin{array}{l}\text { No/mild ROP } \\
(n=21)\end{array}$ & $\begin{array}{l}\text { Severe ROP } \\
(n=22)\end{array}$ & $\begin{array}{l}\text { Controls } \\
(n=26)\end{array}$ & $p$ & 1 vs. 2 & 1 vs. 3 & 2 vs. 3 \\
\hline Male/female, $n$ & $11 / 10$ & $10 / 12$ & $9 / 17$ & & & & \\
\hline \multicolumn{8}{|l|}{ Neonatal anthropometrics } \\
\hline BW, g & $850(719,986)$ & $830(699,960)$ & $3,440(3,323,3,563)$ & $<0.001$ & & & \\
\hline BW SDS & $-0.83(-1.31,-0.35)$ & $-0.34(-0.86,0.09)$ & $-0.18(-0.61,0.26)$ & 0.13 & & & \\
\hline GA, weeks & $26.0(25.5,26.5)$ & $25.5(25.0,26.0)$ & $39.6(39.1,40.1)$ & $<0.001$ & & & \\
\hline \multicolumn{8}{|l|}{ Perinatal characteristics } \\
\hline Maternal age, years & $34(32,36)$ & $31(28,33)$ & $31(28,33)$ & 0.07 & & & \\
\hline Paternal age, years & $34(29,39)$ & $36(33,40)$ & $34(30,38)$ & 0.76 & & & \\
\hline Maternal height, $\mathrm{cm}$ & $165(162,168)$ & $169(166,172)$ & $165(162,168)$ & 0.06 & & & \\
\hline Paternal height, $\mathrm{cm}$ & $181(179,184)$ & $179(176,181)$ & $178(175,181)$ & 0.21 & & & \\
\hline Target height $\mathrm{cm}$ & $175(171,179)$ & $173(169,177)$ & $174(170,187)$ & 0.77 & & & \\
\hline Maternal education level, mean 2-7 & $4.0(3.4,4.6)$ & $4.2(3.6,4.8)$ & $4.0(3.5,4.6)$ & 0.85 & & & \\
\hline Paternal education level, mean 2-7 & $4.6(3.9,5.2)$ & $4.2(3.5,4.8)$ & $4.1(3.5,4.7)$ & 0.51 & & & \\
\hline Maternal pregnancies, $n$ & $2.8(2.2,3.4)$ & $2.5(1.9,3.1)$ & $1.9(1.3,2.4)$ & 0.09 & & & \\
\hline Siblings, $n$ & $0.65(0.3,1.0)$ & $0.91(0.5,1.3)$ & $0.73(0.4,1.1)$ & 0.60 & & & \\
\hline \multicolumn{8}{|l|}{ Maternal smoking during pregnancy } \\
\hline (no/yes), \% & $88 / 13$ & $88 / 13$ & $95 / 5$ & $0.67^{\mathrm{a}}$ & & & \\
\hline Fertility problems (no/yes), \% & $89 / 11$ & $88 / 13$ & $95 / 5$ & $0.70^{\mathrm{a}}$ & & & \\
\hline Maternal diabetes( no/yes), \% & $100 / 0$ & $95 / 5$ & $100 / 0$ & $0.35^{\mathrm{a}}$ & & & \\
\hline Maternal preeclampsia (no/yes), \% & $84 / 16$ & $74 / 26$ & $100 / 0$ & $0.06^{\mathrm{a}}$ & & & \\
\hline Mode of delivery (vaginal/ section), \% & $32 / 68$ & $80 / 20$ & $100 / 0$ & $<0.001^{\mathrm{a}}$ & & & \\
\hline Prenatal cortisol (no/yes), \% & $84 / 16$ & $79 / 21$ & $100 / 0$ & $0.07^{\mathrm{a}}$ & & & \\
\hline BPD (no/yes), \% & $67 / 33$ & $27 / 73$ & $100 / 0$ & $<0.001^{\mathrm{a}}$ & & & \\
\hline IVH (no/yes), \% & $62 / 38$ & $55 / 45$ & - & $0.62^{\mathrm{a}}$ & & & \\
\hline PVL (no/yes), \% & $71 / 29$ & $77 / 23$ & - & $0.66^{\mathrm{a}}$ & & & \\
\hline \multicolumn{8}{|l|}{ Current anthropometrics } \\
\hline Age at follow-up, years & $22(21.86,22.7)$ & $23(22.3,23.3)$ & $23(22.0,23.0)$ & 0.21 & & & \\
\hline Height, $\mathrm{cm}$ & $170(166,175)$ & $170(166,175)$ & $175(172,180)$ & 0.12 & & & \\
\hline Difference from target height, $\mathrm{cm}$ & $-3.7(-6.0,-1.5)$ & $-3.4(-5.6,-1.2)$ & $2.2(0.2,4.1)$ & $<0.001$ & 0.84 & $<0.001$ & $<0.001$ \\
\hline Weight, kg & $63(57,69)$ & $67(62,73)$ & $73(67,78)$ & 0.07 & & & \\
\hline BMI, $\mathrm{kg} / \mathrm{m}^{2}$ & $22(20.2,23.2)$ & $23(21.6,24.5)$ & $24(21.2,24.9)$ & 0.17 & & & \\
\hline Head circumference, $\mathrm{cm}$ & $55(54,56)$ & $56(55,57)$ & $57(56,58)$ & 0.007 & & & \\
\hline Waist circumference, $\mathrm{cm}$ & $83(79,88)$ & $89(85,93)$ & $86(82,90)$ & 0.21 & & & \\
\hline Waist-to-height ratio & $0.49(0.47,0.52)$ & $0.52(0.50,0.55)$ & $0.49(0.47,0.51)$ & 0.09 & & & \\
\hline Hip circumference, $\mathrm{cm}$ & $91(86,95)$ & $95(91,100)$ & $97(93,101)$ & 0.09 & & & \\
\hline \multicolumn{8}{|l|}{ Current characteristics } \\
\hline \multicolumn{8}{|l|}{ Current smoking or snuff use } \\
\hline (no/yes/missing), \% & $83 / 17 / 3$ & $82 / 18 / 0$ & $72 / 28 / 0$ & $0.45^{\mathrm{a}}$ & & & \\
\hline Physical activity, h/week & $5.3(3.3,7.3)$ & $2.2(0.3,4.0)$ & $4.8(3.2,6.5)$ & 0.07 & & & \\
\hline Self-reported wakening period, $\mathrm{h}$ & $16.3(15.5,17.1)$ & $15.7(14.9,16.5)$ & $15.5(14.9,16.5)$ & 0.35 & & & \\
\hline Self-reported sleeping period, h & $7.7(6.9,8.5)$ & $8.3(7.5,9.1)$ & $8.5(7.8,9.3)$ & 0.30 & & & \\
\hline
\end{tabular}

Values are presented as the mean $(95 \% \mathrm{CI})$. Statistical analysis: analysis of variances (ANOVA), followed by post hoc Fischer test unless stated otherwise. BMI, body mass index; BPD, bronchopulmonary dysplasia; IVH, intraventricular hemorrhage; PVL, periventricular leukomalacia; SDS, standard deviation score. ${ }^{a}$ Pearson $\chi^{2}$ test.

\section{Materials and Methods}

\section{Subjects}

Follow-up BP measurements at age 20-25 years were performed in 69 individuals. Study participants included ex-preterms $(n=43)$ with a postmenstrual age of $\leq 30$ weeks and full-term normal-weight controls $(n=26)$ born in Stockholm between 1988 and 1993. In the initial cohort, infants with birth weights (BW)
$<1,500 \mathrm{~g}$ were included. During the neonatal period, 51 of 291 infants died.

All 28 subjects treated for severe ROP in the primary cohort were invited to participate in the present study and 22 accepted. In total, 125 controls were included in the primary cohort, 55 were randomly selected and invited, and 26 participated.

Infants with no/mild ROP and GA $<28$ weeks at birth were included as preterm controls $(n=42)$. Twenty-one agreed to par- 
Table 2. BP data

\begin{tabular}{|c|c|c|c|c|c|c|c|}
\hline & $\begin{array}{l}\text { No/mild ROP } \\
(n=21)\end{array}$ & $\begin{array}{l}\text { Severe ROP } \\
(n=22)\end{array}$ & $\begin{array}{l}\text { Controls } \\
(n=26)\end{array}$ & $p$ & 1 vs. 3 & 2 vs. 3 & 1 vs. 2 \\
\hline \multicolumn{8}{|l|}{ Office BP } \\
\hline Mean systolic BP right arm & $124(119,129)$ & $131(127,136)$ & $124(120,127)$ & 0.015 & 0.82 & 0.007 & 0.019 \\
\hline Mean systolic BP left arm & $125(120,129)$ & $131(126,136)$ & $123(119,127)$ & 0.042 & 0.63 & 0.017 & 0.06 \\
\hline Mean diastolic BP right arm & $75(72,78)$ & $77(74,81)$ & $75(72,78)$ & 0.38 & & & \\
\hline Mean diastolic BP left arm & $75(72,79)$ & $77(73,80)$ & $74(71,77)$ & 0.45 & & & \\
\hline \multicolumn{8}{|l|}{ Ambulatory BP } \\
\hline 24-h systolic BP & $123(120,127)$ & $127(122,131)$ & $124(120,127)$ & 0.40 & & & \\
\hline 24-h diastolic BP & $72(70,74)$ & $73(69,76)$ & $70(68,72)$ & 0.33 & & & \\
\hline 24-h pulse pressure & $51(49,54)$ & $54(51,58)$ & $52(50,55)$ & 0.33 & & & \\
\hline 24-h heart rate, beats/min & $74(69,78)$ & $71(67,76)$ & $73(69,77)$ & 0.72 & & & \\
\hline 24-h systolic recordings above $140 \mathrm{~mm} \mathrm{Hg}, \%$ & $19(9,28)$ & $28(16,40)$ & $15(9,21)$ & $0.10^{\mathrm{a}}$ & & & \\
\hline Day systolic BP & $127(123,131)$ & $130(126,135)$ & $126(123,128)$ & 0.22 & & & \\
\hline Day systolic hypertension, \% & $19(7,37)$ & $38(15,61)$ & $4(0,12)$ & $0.012^{\mathrm{a}}$ & & & \\
\hline Day diastolic BP & $76(73,79)$ & $76(73,79)$ & $74(71,76)$ & 0.35 & & & \\
\hline Day diastolic hypertension, $\%$ & $5(1,15)$ & $14(0,31)$ & 0 & $0.11^{\mathrm{a}}$ & & & \\
\hline Day pulse pressure & $51(48,54)$ & $54(51,57)$ & $52(50,55)$ & 0.37 & & & \\
\hline Night systolic BP & $114(110,119)$ & $118(113,124)$ & $113(109,117)$ & 0.18 & & & \\
\hline Night systolic hypertension, \% & $19(7,37)$ & $43(20,66)$ & $15(0,30)$ & $0.07^{\mathrm{a}}$ & & & \\
\hline Night diastolic BP & $62(59,65)$ & $63(59,67)$ & $60(57,63)$ & 0.50 & & & \\
\hline Night pulse pressure & $53(50,56)$ & $56(52,59)$ & $53(50,55)$ & 0.31 & & & \\
\hline Night systolic recordings above $120 \mathrm{~mm} \mathrm{Hg}$, \% & $25(13,37)$ & $42(26,58)$ & $25(15,34)$ & $0.09^{\mathrm{a}}$ & & & \\
\hline Nocturnal dipping, \% & $48(24,71)$ & $45(21,69)$ & $58(37,78)$ & $0.65^{\mathrm{a}}$ & & & \\
\hline $\mathrm{WCH}, \%$ & $19(1,37)$ & $33(11,55)$ & $27(9,45)$ & $0.57^{\mathrm{a}}$ & & & \\
\hline Morning cortisol, $\mu \mathrm{g} / \mathrm{L}$ & $21(16,26)$ & $22(16,27)$ & $22(15,28)$ & 0.84 & & & \\
\hline Evening cortisol, $\mu \mathrm{g} / \mathrm{L}$ & $6.8(5.3,8.2)$ & $9.6(7.6,11.7)$ & $7.9(6.8,9.0)$ & 0.035 & 0.30 & 0.11 & 0.012 \\
\hline
\end{tabular}

Data are presented as $\mathrm{mm} \mathrm{Hg}(95 \% \mathrm{CI})$ unless otherwise stated. The 2 ROP groups were born before gestational week 28 , except for 3 individuals in the severe ROP group, born before week 30 (birth weight <1,250 g), between 1988 and 1993. Statistical analysis: analysis of variances (ANOVA), followed by post hoc Fischer test unless stated otherwise. BP, blood pressure; WCH, white coat hypertension. ${ }^{\text {a }}$ Pearson $\chi^{2}$ test.

ticipate in the study. Participants and nonparticipants showed no differences in GA and BW within the groups.

The study protocol was approved by the ethics committee at Karolinska Solna, Stockholm. All subjects provided written informed consent.

\section{Definitions}

GA was determined by ultrasound during early pregnancy. Standard deviation scores (SDS) were based on the Swedish reference curve at birth [3] and adulthood (Tables 1,2).

\section{Morbidity Examination: ROP Evaluation}

ROP was classified according to an international classification [4]. Each child was classified according to the most advanced ROP stage observed.

Subjects were divided into 2 groups according to ROP staging; no/mild ROP (stage $\leq 2 ; n=21$ ) or severe ROP (stage $\geq 3 ; n=22$; Table 1). All individuals with severe ROP were treated with retinal ablation (cryotherapy) according to guidelines current at the time of the study [5].

Maternal and Heredity Factors, Neonatal Information,

Self-Reported Physical Activity, and Smoking Habits

The maternal medical history and neonatal information was obtained at the time of the initial study (Table 1). Current subject characteristic information was obtained at the time of the study (Table 1). Two subjects in the severe ROP group took antihypertensive medication.

\section{Data Collection: BP Measurements}

An experienced nurse recorded each subject's office BP in both arms and was unaware which group the participant represented. An oscillometric automatic BP monitor (Omron HEM-7201; Omron Healthcare, Kyoto, Japan) was used, with the subject in a supine position after 10 min of rest. Office BP was calculated as the mean of 2 recordings.

Each subject's ambulatory BP was obtained using a noninvasive oscillometric system (Spacelabs 90207, Spacelabs Inc., Redmond, WA, USA) applied on the nondominant arm. The measurement period was at least $24 \mathrm{~h}$, with readings every $20 \mathrm{~min}$. Means were calculated over the entire $24-\mathrm{h}$ period, and for day (6 a.m. to 11 p.m.) and night (11 p.m. to 6 a.m.).

Morning and evening salivary cortisol (immunochemistry, radioimmunoassay, and reference morning [10-46 nmol/L] and evening [3.2-15 nmol/L] levels) were obtained 1 day prior to the $\mathrm{BP}$ measurements.

\section{Definitions}

The target height (in centimeters) was defined as the maternal height + paternal height (adding $13[$ male]/subtracting $13[\mathrm{fe}-$ 
male]) divided by 2 . Hypertension was defined as the mean systolic daily ambulatory $\mathrm{BP}>135 \mathrm{~mm} \mathrm{Hg}$ and/or under BP medication or a mean systolic nighttime BP $>120 \mathrm{~mm} \mathrm{Hg}$ [6]. Diastolic hypertension was defined as daily ambulatory $\mathrm{BP}>85 \mathrm{~mm} \mathrm{Hg}$ [6]. Nocturnal dipping was defined as a mean nighttime systolic BP $10 \%$ or more below that of the mean daytime systolic BP. White coat hypertension was considered present when the office systolic BP level was at the 95th percentile or higher, with a systolic ambulatory average BP at the 90th percentile or lower and compared with Swedish reference values [7].

\section{Statistics}

Individuals' anthropometric data, $\mathrm{BP}$, and salivary cortisol levels are presented as the mean and 95\% confidence intervals (CI). The comparison between groups was made by analysis of variance and post hoc Fischer test. The Pearson $\chi^{2}$ test was used. Forward stepwise multiple regression analysis was performed with systolic $\mathrm{BP}$ as a dependent variable. $p<0.05$ was considered statistically significant. Statistical analyses were performed using Statistica StatSoft, version 10 (Statistica, Tulsa, OK, USA).

\section{Results}

Table 1 shows data for the 69 subjects at birth and adulthood. The 2 ex-preterm groups did not reach their target height compared with the controls.

Subjects with no/mild ROP had lower evening cortisol levels compared with those with severe ROP. The adult severe ROP group had approximately $7.4 \mathrm{~mm} \mathrm{Hg}$ higher systolic office BP than the no/mild ROP $(p=0.019)$ and control ( $p=0.007$ ) groups (Table 2). Additionally, the severe ROP group had a higher incidence of daily systolic hypertension and trended towards a difference in nighttime systolic hypertension (Table 2).

In forward stepwise regression analysis with systolic daily ambulatory $\mathrm{BP}$ as the dependent variable, morning cortisol levels $(\beta=0.268, p=0.024)$, height $(\beta=0.239$, $p=0.043)$, and severe ROP $(\beta=0.235, p=0.047)$ were included as independent predictors (adjusted $r^{2}=0.15$, $p<0.005, n=65)$. GA, BW SDS, neonatal bronchopulmonary dysplasia (BPD), and graded physical activity had no impact when included in the analysis. With left arm office systolic BP as a dependent variable, severe $\operatorname{ROP}(\beta=0.331, p=0.004)$, height $(\beta=0.400, p<0.001)$, and morning cortisol levels $(\beta=0.236, p=0.029)$ were significant predictors (adjusted $r^{2}=0.29, p<0.0001, n=$ 65 ) independent of GA, BW SDS, or BPD. Less physical activity was a nonsignificant predictor $(\beta=-0.169, p=$ $0.14)$.

\section{Discussion}

Subjects with severe ROP as infants, indicating severe early abnormal retinal vessel development, had increased office systolic BP and higher incidences of hypertension in daily systolic ambulatory BP as adults. However, adults born preterm with no/mild ROP did not differ from controls in office or ambulatory BP recordings. Higher morning salivary cortisol, taller height, and severe ROP were related to higher ambulatory daily systolic BP independent of GA, BW SDS, and neonatal BPD.

Morning salivary cortisol was weakly related to office and daytime ambulatory systolic BP. Nearly all of the subjects had salivary cortisol within the normal range. In older men born at term, high salivary cortisol has been associated with hypertension [8].

In the Express study, approximately $70 \%$ of extremely preterm infants born at GA $<27$ weeks developed ROP and one-fifth needed laser therapy [4]. Low weight or poor weight gain, hyperglycemia, and other neonatal morbidities correlate with more severe ROP [9]. Infants with severe ROP experience an early catabolic period with metabolic derangement that may affect cardiovascular development.

We found differences in systolic but not in diastolic BP. This is in accordance with BP findings in another group of preterm children with severe ROP. At the age of 4 years, these infants presented with higher mean office arterial pressure [2]. In a large retrospective meta-analysis, however, ROP was not associated with increased BP in ex-preterm subjects [10].

In our study, about $40 \%$ of severe ROP subjects had systolic daytime and nighttime hypertension. In a retrospective study, at a mean age of 52 years, nighttime mean systolic BP was the most significant predictor of cardiac events [6]. Although the sample was small, our results indicate that subjects with severe ROP need early follow-up for $\mathrm{BP}$ control and, if required, treatment.

One limitation of this study was the relatively low participation rate, although no simple signs of selection bias were detected between the participating and non-participating subjects. The causal relationship of these findings, as well as the effect on future morbidity, should be investigated in greater depth.

\section{Acknowledgements}

We express our gratitude to Lena Swartling for technical assistance, Linda Nilson for BP arrangements, and Birgitta Böhm for providing neonatal information.
Kistner/Jacobson/Östergren/Hellström 


\section{Disclosure Statement}

The authors have no conflicts of interest to declare.

\section{Funding Sources}

This study was supported by the Allmänna BB Foundation, Martina Lundgren, Herman Svensson, the Swedish Medical Society, and by grants from Soderhospital, the Karolinska Insitutet, the Sigvard and Marianne Bernadotte Research Foundation for Children's Eye Care. We also received grants from the Swedish Medical Research Council (No. 2011-2432) and the Swedish government (No. ALFGB2770).

\section{References}

1 Evensen KA, Steinshamn S, Tjonna AE, Stolen T, Hoydal MA, Wisloff U, Brubakk AM, Vik T: Effects of preterm birth and fetal growth retardation on cardiovascular risk factors in young adulthood. Early Hum Dev 2009;85:239-245.

2 Kistner A, Sigurdsson J, Niklasson A, Lofqvist C, Hall K, Hellstrom A: Neonatal IGF-1/ IGFBP-1 axis and retinopathy of prematurity are associated with increased blood pressure in preterm children. Acta Paediatr 2014;103: 149-156.

3 Niklasson A, Albertsson-Wikland K: Continuous growth reference from 24 th week of gestation to 24 months by gender. BMC Pediatr 2008;8:8.

4 Stahl A, Hellstrom A, Smith LE: Insulin-like growth factor-1 and anti-vascular endothelial growth factor in retinopathy of prematurity: has the time come? Neonatology 2014;106: 254-260.
5 Cryotherapy for Retinopathy of Prematurity Cooperative Group: Multicenter trial of cryotherapy for retinopathy of prematurity: preliminary results. Arch Ophthalmol 1988;106: 471-479.

6 Hermida RC, Smolensky MH, Ayala DE, Portaluppi F, Crespo JJ, Fabbian F, Haus E, Manfredini R, Mojon A, Moya A, Pineiro L, Rios MT, Otero A, Balan H, Fernandez JR: 2013 ambulatory blood pressure monitoring recommendations for the diagnosis of adult hypertension, assessment of cardiovascular and other hypertension-associated risk, and attainment of therapeutic goals (summary). Joint recommendations from the International Society for Chronobiology (ISC), American Association of Medical Chronobiology and Chronotherapeutics (AAMCC), Spanish Society of Applied Chronobiology, Chronotherapy, and Vascular Risk (SECAC), Spanish Society of Atherosclerosis (SEA), and
Romanian Society of Internal Medicine (RSIM) (in Spanish). Clin Investig Arterioscler 2013;25:74-82.

7 Nystrom F, Malmstrom O, Karlberg BE, Ohman KP: Twenty-four hour ambulatory blood pressure in the population. J Intern Med 1996;240:279-284.

8 Schoorlemmer RM, Peeters GM, van Schoor NM, Lips P: Relationships between cortisol level, mortality and chronic diseases in older persons. Clin Endocrinol 2009;71:779-786.

9 Quinn GE, Dobson V, Saigal S, Phelps DL, Hardy RJ, Tung B, Summers CG, Palmer EA: Health-related quality of life at age 10 years in very low-birth-weight children with and without threshold retinopathy of prematurity. Arch Ophthalmol 2004;122:1659-1666.

10 Hovi P, Vohr B, Ment LR, Doyle LW, McGarvey $\mathrm{L}$, Morrison $\mathrm{KM}$, et al: Blood pressure in young adults born at very low birth weight. Hypertens 2016;68:880-887. 